Authors have nothing to disclose with regard to commercial support.

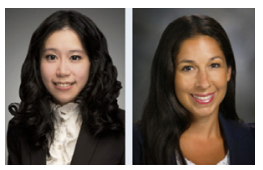

\section{BRIDGING GAPS IN TRANSITION TO PRACTICE}

\section{To the Editor:}

We read with great interest the article by Sterbling and colleagues ${ }^{1}$ entitled "Initial Report on Young Cardiothoracic Surgeons' First Job: From Searching to Securing and the Gaps in Between." In their study, respondents reported needing more resources and support for salary guidelines navigation $(77 \%)$, contract negotiation $(73 \%)$, identification of job opportunities $(61 \%)$, marketing oneself $(51 \%)$, financial management $(24 \%)$, and interview preparation $(14 \%)$. The importance of learning how to negotiate was apparent, with those who engaged in negotiation ultimately reporting a higher median starting salary relative to nonnegotiators $(P=.05)$. Despite being limited by a suboptimal response rate and lack of respondent stratification by training paradigm and subspecialty, Sterbling and colleagues ${ }^{1}$ succeeded in shedding light on the opaque process of seeking employment and the need for concerted career resources to be developed to support the newest generation of cardiothoracic surgeons.

As attention is cast on some of these challenges for early career surgeons, we, as a specialty, must contemplate ways in which we may provide support and resources to those entering our field. The Journal has successfully addressed many such needs through the Young Surgeon's Notes series, ${ }^{2}$ which has been a phenomenal resource for the youngest generations of cardiothoracic surgeons. In addition, the American Association for Thoracic Surgery (AATS) and the AATS Foundation have developed a wide array of scholarships and award opportunities for early career academicians, empowering them to learn new techniques and initiate novel research investigations. The AATS Leadership Academy ${ }^{3}$ offers guidance in building important skill sets of particular interest to early-career surgeons. Likewise, a number of awards, ${ }^{4}$ scholarships, mentoring initiatives, traveling fellowships, and tailored educational programs are offered through the Thoracic Surgery Foundation,

\footnotetext{
The Editor welcomes submissions for possible publication in the Letters to the Editor section that consist of commentary on an article published in the Journal or other relevant issues. Authors should: • Include no more than 500 words of text, three authors, and five references. • Type with double-spacing. • See http://jtcs.ctsnetjournals.org/ misc/ifora.shtml for detailed submission instructions. • Submit the letter electronically via jtcvs.editorialmanager.com. Letters commenting on an article published in the JTCVS will be considered if they are received within 6 weeks of the time the article was published. Authors of the article being commented on will be given an opportunity of offer a timely response ( 2 weeks) to the letter. Authors of letters will be notified that the letter has been received. Unpublished letters cannot be returned.
}

Women in Thoracic Surgery, Thoracic Surgery Residents Association, CTSNet, and regional cardiothoracic surgical societies such as the Southern Thoracic Surgical Association, the Western Thoracic Surgical Association, the Eastern Cardiothoracic Surgical Society, and the General Thoracic Surgery Club - all of which may be of particular utility to early-career surgeons, trainees and medical students.

Recognizing that our specialty's organizations each have a number of complementary resources to offer the early-career surgeon, we also encourage the Journal's readership to familiarize themselves with the Society of Thoracic Surgeons Workforce on Career Development (https://www. sts.org/resources/career-resources), established with the goal of developing tools to assist cardiothoracic surgeons with career navigation during the first 7 years of practice. The Workforce accomplishes this goal through a well-developed career resources website with answers to frequently asked questions, annual meeting programming, and continuously updated digital content, including monthly blogs, and quarterly TweetChats ${ }^{5}$ with the Twitter handle @ CTSurgCareers and the hashtag \#CTCareers. Importantly, by using multimodality techniques to reach the cardiothoracic surgical community, such resources provide knowledge and networking opportunities for early careerists.

Ensuring that new cardiothoracic surgeons achieve clinical, academic, financial, and personal success should be the goal of our specialty. Further, by showing prospective cardiothoracic surgical applicants that the field is one in which they will be welcomed, nurtured, and valued may help ensure that our specialty continues to attract the best and brightest.

$$
\begin{array}{r}
\text { Jessica G. Y. Luc, MD } \\
\text { Mara B. Antonoff, } M D^{b} \\
\text { a Division of Cardiovascular Surgery } \\
\text { Department of Surgery } \\
\text { University of British Columbia } \\
\text { Vancouver, British Columbia, Canada } \\
{ }^{b} \text { Department of Thoracic and Cardiovascular Surgery } \\
\text { University of Texas MD Anderson Cancer Center } \\
\text { Houston, Tex }
\end{array}
$$

\section{References}

1. Sterbling HM, Molena D, Rao SR, Stein SL, Litle VR. Initial report on young cardiothoracic surgeons' first job: from searching to securing and the gaps in between. J Thorac Cardiovasc Surg. 2019;158:632-41.

2. Vaporciyan AA, Yang SC, Fann JI. The young surgeons' page. J Thorac Cardiovasc Surg. 2019;157:669-70.

3. Reddy V, Ikonomidis J, Crawford FA Jr. The AATS academy: development of a unique concept in medical education. J Thorac Cardiovasc Surg. 2011;141:1101-2.

4. Allen JG, Weiss ES, Patel ND, Alejo DE, Fitton TP, Williams JA, et al. Inspiring medical students to pursue surgical careers: outcomes from our cardiothoracic surgery research program. Ann Thorac Surg. 2009;87:1816-9.

5. Luc JG, Varghese TK Jr, Antonoff MB. Participating in a TweetChat: practical tips from the thoracic surgery social media network (\#TSSMN). Ann Thorac Surg. 2019;107:e229-33.

https://doi.org/10.1016/j.jtcvs.2019.06.026 